\title{
Stress-Reducing Effects of Playing a Casual Video Game among Undergraduate Students
}

\author{
Veeral Desai ${ }^{1,2} \cdot$ Arnav Gupta $^{3}$ - Lucas Andersen ${ }^{4} \cdot$ Bailey Ronnestrand $^{4}$. \\ Michael Wong ${ }^{1,4,5}$ (iD
}

Accepted: 8 January 2021/ Published online: 11 March 2021

(C) Associação Brasileira de Psicologia 2021

\begin{abstract}
Objective To assess the potential effectiveness of playing a simple, casual video game (Flower) in reducing stress relative to participating in a mindfulness-meditation session (body scan) among undergraduate students. Eighty undergraduate student participants (mean age $=19.46$ years, $S D=1.43$; gender: 48 females, 29 males, 3 preferred not to answer) were assigned to one of two groups in alternating order: one who played Flower and the comparison group who participated in a body scan, each lasting $20 \mathrm{~min}$. Psychological and physiological stress measurements were made before and after each intervention. Self-perceived psychological stress was measured using a modified version of the nine-item Psychological Stress Measure (PSM-9), and physiological stress (heart rate, systolic and diastolic blood pressure) was measured using an electronic blood-pressure cuff. The results were analyzed with a 2 (measurement: pre, post) $\times 2$ (intervention: video game, mindfulness-meditation) mixed model analysis of variance (ANOVA) for each of the four outcome measures. There was a statistically significant reduction (pre- to post-intervention) across all outcome measures. Notably, there was a significant measurement $\times$ intervention interaction $(p<.001)$ for the psychological stress measure; participants in the mindfulness-meditation group reported greater stress reduction after the intervention than participants in the video game group. Although these results suggest mindfulness-meditation provides a slight advantage for stress reduction than casual video games, the similarity in reduction across all physiological measures between the two interventions nevertheless suggests casual video games may also be an effective medium. This finding is especially promising given casual video games' accessibility, ease of use, and popularity among students. These results may inform initiatives by colleges and universities to better support students during peak times of stress and especially during the current COVID-19 pandemic.
\end{abstract}

Michael Wong

wongm8@mcmaster.ca

Extended author information available on the last page of the article 
Keywords Casual video games · Stress reduction · Undergraduate students · Mindfulness · Meditation · Body scan

Undergraduate student stress is prevalent across the world, which can lead to low selfesteem and a low external locus of control (Abouserie 1994; Campbell et al. 1992; Saleh et al. 2017; Stanley and Bhuvaneswari 2016; Zhang et al. 2012). A recent survey by the American College Health Association (2019) revealed that nearly $60 \%$ of students in the USA reported experiencing above-average levels of stress within the last 12 months of completing the survey, and about 35\% reported that stress had negatively impacted their studies in the last year. Indeed, accumulating evidence suggests stress can negatively impact learning and memory retrieval (Vogel and Schwabe 2016). As such, a large number of studies have been published highlighting the effectiveness of a variety of stress-reducing techniques, including meditation, yoga-based programs, counseling services, listening to music, adult coloring, nature therapy, and pet therapy (Barker et al. 2010; Chafin et al. 2004; Hansen et al. 2017; Jiang et al. 2016; Mantzios et al. 2019; Mantzios and Giannou 2018; Regehr et al. 2013; Shearer et al. 2016; Warnecke et al. 2011).

More recently, there has been growing interest in the stress-reducing effects of mindfulness, defined by Kabat-Zinn (1994) as "paying attention in a particular way: on purpose, in the present moment, and non-judgmentally" (p. 4). Mindfulness is popularly achieved through guided meditation, with an increasing number of studies showing its effectiveness in reducing both psychological and biological markers of stress, e.g., blood pressure and heart rate (Barnes et al. 1999, 2001; Burton et al. 2017; Hoge et al. 2018; Kang et al. 2009; Khoury et al. 2015). Intriguingly, Palmer and Rodger (2009) observed an inverse relationship between self-reported levels of mindfulness and stress among university students. Moreover, the literature has highlighted how mindfulness-meditation can help college students manage their stress in response to the academic, cognitive, and emotional challenges associated with university life (Bamber and Schneider 2016; Huberty et al. 2019; Lemay et al. 2019; Ratanasiripong et al. 2015; Rosenzweig et al. 2003; Warnecke et al. 2011).

Although mindfulness-meditation has shown promise as a method of stress reduction, it may not be a favored technique among undergraduate students. Video games, by contrast, appear to be particularly popular among this population (Thomas and Martin 2010). In 2008, the Pew Research Center reported that $57 \%$ of individuals who have some form of post-secondary education are video game players; this statistic increases substantially to $76 \%$ for current students (Lenhart et al. 2008). In addition to video games' popularity as a pastime, several studies have reported that people of all ages turn to video games to cope with stress (Bledsoe et al. 2018; Ferguson and Olson 2013; Reinecke 2009; Wack and Tantleff-Dunn 2009; Whitbourne et al. 2013); and accumulating evidence has linked playing video games to relaxation and stress reduction (Jones et al. 2014; Rieger et al. 2015; Roy and Ferguson 2016; Soyoof and McLay 2019).

Although research examining the therapeutic effects of serious video games has started to gain traction, the stress-reducing potential of simple, easy-to-learn casual video games that can be played for a short duration has not been well researched. For example, in a recent systematic review, Pine et al. (2020) reported only three studies that examined the impact of playing casual video games on stress, with all three studies reporting that playing casual video games led to lower levels of stress (Fish et al. 2014; 
Rupp et al. 2017; Russoniello et al. 2009). To date, however, no studies have investigated how playing a casual video game compares to the more widely studied method of mindfulness-meditation in reducing stress.

To that end, in the present study, we assessed whether playing a casual video game could serve as a viable alternative to participating in a mindfulness-meditation session as a method of stress reduction among undergraduate students. Moreover, given the demands of postsecondary education, we were also interested in investigating the potential stress-reducing effects of these interventions if used for a brief period of time (20 min in our study). For our video game intervention, we used "Flower," a casual free-form video game with minimal instruction that, in contrast to more traditional video games, can be played for short periods at a time. In addition to its ease of use, another feature of Flower that makes it particularly attractive is it is accessible on a variety of platforms (e.g., iOS, PlayStation, Windows).

For our mindfulness-meditation intervention, we used a body scan, a form of meditation in which the participant is made consciously aware of the different parts of their body. We decided to utilize a body scan meditation due to its simplicity and link with the wellestablished mindfulness-based stress reduction program (MBSR), which has shown much promise in improving a number of health outcomes, including stress reduction (Grossman et al. 2004; Hughes et al. 2013; Levoy et al. 2017; Momeni et al. 2016; Nyklíček et al. 2013; Parswani et al. 2013; Rush and Sharma 2017; Shapiro et al. 1998). Additionally, some studies have shown that body scan meditation alone leads to similar results (Corbett et al. 2019; Ditto et al. 2006; Schultchen et al. 2019; Ussher et al. 2014).

Ultimately, we aimed to assess the relative effectiveness of playing a casual video game to participating in a mindfulness-meditation session. If we find that playing a casual video game leads to similar, if not better, levels of stress reduction to participating in a mindfulness-meditation session, this would suggest casual video games may be an effective stress-reducing intervention for undergraduate students, which is especially promising given their accessibility, ease of use, and popularity among this population.

\section{Method}

\section{Participants}

A total of 80 undergraduate students (mean age $=19.46$ years, $S D=1.43$; gender: 48 females, 29 males, 3 preferred not to answer) from a Midwestern university in the USA participated in the present study for course credit (Table 1). Participants self-enrolled via an advertisement posted on an online participant management platform (Sona Systems). We excluded individuals who had been diagnosed with anxiety and/or depressive disorders in order to better investigate our interventions on typical undergraduate students. This study was approved by the local ethics review board.

\section{Materials and Measurements}

The video game intervention used in the present study was the video game, Flower (developed by "Thatgamecompany"). In this game, the user controls the wind, moving 
Table 1 Participant demographics

\begin{tabular}{llll}
\hline Demographic & Mindfulness-meditation & Video game & All \\
\hline Age & & & 18 \\
Minimum & 18 & 18 & 27 \\
Maximum & 23 & 27 & 19.46 \\
$M$ & 19.50 & 19.43 & 1.43 \\
$S D$ & 1.24 & 1.62 & 29 \\
Gender & 13 & & 48 \\
Male & 26 & 16 & 3 \\
Female & 1 & 22 & 2 \\
PNTA & 13 & 22 & 48 \\
\hline
\end{tabular}

Note. This table lists the age and gender of the participants in the present study

$P N T A$, prefer not to answer

an initial flower petal through the air, which participants in our study accomplished by tilting and turning a 10.5-inch iPad Pro (Apple Inc.). Flying the petal close to flowers results in the initial petal being followed by subsequent flower petals, eventually building a trail of petals. The mindfulness-meditation intervention featured a guided body scan session (played out loud via a 21.5-inch iMac, Apple Inc.) adapted from the theory of yoga nidra (Saraswati 2009) and courteously provided by Dr. Parmjit Singh (McMaster University).

The participant sat alone in the center of a small, relatively empty room at the university containing only some furniture (e.g., iMac on desk, chair for participant, file cabinet), most of which were used in the experiment. The iMac from which the body scan was played was situated to the right of the participant.

To measure psychological stress, we administered a modified version of the nineitem Psychological Stress Measure (PSM-9) (Lemyre and Tessier 2003). The original survey has been validated and used in other studies (Lemyre and Lalande-Markon 2009; McFadden et al. 2012). The modification we made to the PSM-9 was very minor; rather than asking participants to reflect on their mood in the last 4 to 5 days, we asked participants to reflect on their mood currently (see Table 3 in the Appendix). Cronbach's alpha calculations revealed our modified PSM-9 had fairly good reliability (pre: $\alpha=.77$; post: $\alpha=.81$ ).

To measure physiological stress, we used an Omron 10 Series electronic blood pressure cuff to capture participant heart rate and blood pressure. To minimize potential white coat hypertension, these measurements were taken by an undergraduate student researcher (Myers 2014; Myers et al. 2010). Such physiological measures were used in previous stress-related investigations (Barnes et al. 2001; Ditto et al. 2006; Nyklíček et al. 2013). Additionally, in the typical stress response, cortisol may induce sodium retention and nitric oxide suppression leading to hypertension (due to volume expansion and systemic vasoconstriction) and increased heart rate (Gerra et al. 2001; Kelly et al. 1998). Thus, a reduction in heart rate and blood pressure may be indicative of lowered physiological stress. 


\section{Procedure}

Participants underwent a series of pre-intervention measurements (PSM-9, heart rate, systolic blood pressure, diastolic blood pressure) and were assigned in alternating order to the video game group or the mindfulness-meditation group. Participants were then seated comfortably on a chair in the center of the room and either played Flower or followed a guided body scan session for a duration of $20 \mathrm{~min}$. Once this was complete, participants underwent the pre-intervention measurements once more.

\section{Data Analysis}

Kolmogorov-Smirnov tests revealed the data were non-normally distributed for the pre $(p=.004)$ and post $(p=.009)$ PSM-9 measurements of the video game group; pre ( $p=.027)$ systolic blood pressure measurement of the mindfulness-meditation group; and post $(p=.026)$ diastolic blood pressure measurement of the video game group. Thus, all PSM-9, systolic blood pressure, and diastolic blood pressure data were logtransformed prior to analysis. The results of each of the outcomes measures (PSM-9, heart rate, systolic blood pressure, diastolic blood pressure) were then analyzed with a 2 (measurement: pre, post) $\times 2$ (intervention: video game, mindfulness-meditation) mixed model analysis of variance (ANOVA). Descriptive statistics reported herein reflect the raw data (Manikandan 2010). All statistical analyses were performed using SPSS Statistics v25 (IBM) for MacIntosh.

\section{Results}

\section{PSM-9 Survey}

The ANOVA revealed a significant main effect of measurement, $F(1,78)=159.00$, $p<.001, \eta_{P}^{2}=.67$, indicating that participants reported lower levels of perceived stress after the interventions $(M=2.53, S D=0.81)$ than before $(M=3.30$, $S D=0.89)$. Additionally, there was a main effect of group, $F(1,78)=11.64$, $p=.001, \eta^{2}{ }_{P}=.13$, indicating that participants in the mindfulness-meditation group $(M=3.16, S D=0.97)$ reported lower overall levels of perceived stress than participants in the video game group $(M=3.43, S D=0.79)$. There was also a significant measurement $\times$ intervention interaction, $F(1,78)=18.71, p<.001, \eta_{P}^{2}=.19$. On average, participants in the mindfulness-meditation group (pre: $M=3.16, S D=0.97$; post: $M=2.17, S D=0.67$ ) reported greater stress reduction than participants in the video game group (pre: $M=3.43, S D=0.79$; post: $M=2.88, S D=0.80$ ) (Fig. 1) (See Table 2 for summary statistics of all outcome measures).

\section{Heart Rate}

The ANOVA revealed a significant main effect of measurement, $F(1,78)=52.12$, $p<.001, \eta^{2}=.40$, but not of group. There was no significant measurement $\times$ intervention interaction. On average, heart rate was lower after $(M=71.50$ beats $/ \mathrm{min}, S D=11.36)$ the intervention than before $(M=76.58$ beats/min, $S D=14.21)$ (Fig. 2). 


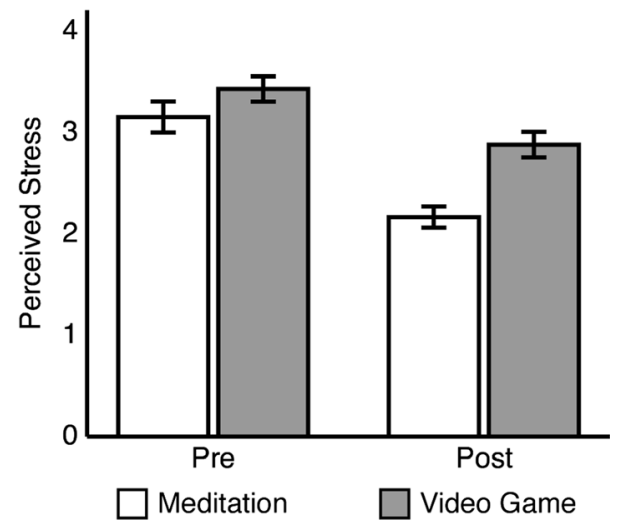

Fig. 1 Pre- and post-PSM-9 scores of participants in the mindfulness-meditation (white bars) and video game (grey bars) groups. Participants overall reported lower PSM-9 scores after participating in the interventions $(p<.001)$. There was greater PSM-9 reduction among participants in the mindfulness-meditation group than participants in the video game group $(p<.001) . M+/-1 S E$

\section{Systolic Blood Pressure}

The ANOVA revealed a significant main effect of measurement, $F(1,78)=40.80$, $p<.001, \eta^{2} P=.34$, but not of group. There was no significant measurement $\times$ intervention interaction. On average, systolic blood pressure was lower after $(M=113.09 \mathrm{mmHG}, S D$ $=12.51)$ the intervention than before $(M=120.23 \mathrm{mmHG}, S D=13.97)$ (Fig. 3$)$.

Table 2 Summary statistics

\begin{tabular}{|c|c|c|c|c|c|c|}
\hline \multirow[b]{2}{*}{ Outcome measure } & \multicolumn{2}{|c|}{ Mindfulness-meditation } & \multicolumn{2}{|c|}{ Video game } & \multicolumn{2}{|l|}{ All } \\
\hline & Pre & Post & Pre & Post & Pre & Post \\
\hline \multicolumn{7}{|l|}{ PSM-9 } \\
\hline$M$ & 3.16 & 2.17 & 3.43 & 2.88 & 3.30 & 2.53 \\
\hline$S D$ & 0.97 & 0.67 & 0.79 & 0.80 & 0.89 & 0.81 \\
\hline \multicolumn{7}{|l|}{ Heart rate } \\
\hline$M$ & 75.68 & 70.39 & 77.48 & 72.60 & 76.58 & 71.50 \\
\hline$S D$ & 13.79 & 10.97 & 14.74 & 11.76 & 14.21 & 11.36 \\
\hline \multicolumn{7}{|l|}{ Systolic BP } \\
\hline$M$ & 118.95 & 111.85 & 121.52 & 114.33 & 120.23 & 113.09 \\
\hline$S D$ & 15.22 & 15.13 & 12.67 & 9.21 & 13.97 & 12.51 \\
\hline \multicolumn{7}{|l|}{ Diastolic BP } \\
\hline$M$ & 71.65 & 70.81 & 71.61 & 69.06 & 71.63 & 69.93 \\
\hline$S D$ & 8.91 & 9.06 & 8.45 & 9.87 & 8.63 & 9.45 \\
\hline
\end{tabular}

Note. This table lists the means and standard deviations of each of the four outcome measures in the present study

PSM-9, Psychological Stress Measure; heart rate measured in beats/minute; systolic and diastolic blood pressure $(\mathrm{BP})$ measured in $\mathrm{mmHG}$ 


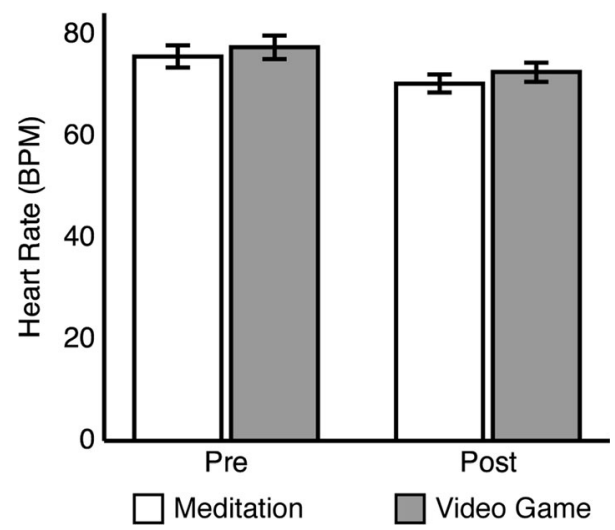

Fig. 2 Pre- and post-heart rate of participants in the mindfulness-meditation (white bars) and video game (grey bars) groups. There was a statistically significant reduction in heart rate in both participant groups after the intervention $(p<.001) . M+/-1 S E$

\section{Diastolic Blood Pressure}

The ANOVA revealed a significant main effect of measurement, $F(1,78)=7.96, p=.006$, $\eta^{2}{ }_{P}=.09$, but not of group. There was no significant measurement $\times$ intervention interaction. On average, diastolic blood pressure was lower after $(M=69.93 \mathrm{mmHG}$, $S D=9.45)$ the intervention than before $(M=71.63 \mathrm{mmHG}, S D=8.63)$ (Fig. 4).

\section{Discussion}

Overall, our data show that playing a casual video game such as Flower for a short duration can be nearly as effective in reducing stress among undergraduate students as participating in a body scan session for the same duration. There was a statistically significant decrease across all four stress measures (PSM-9, heart rate, systolic blood pressure, diastolic blood pressure) pre- to post-intervention. With the exception of

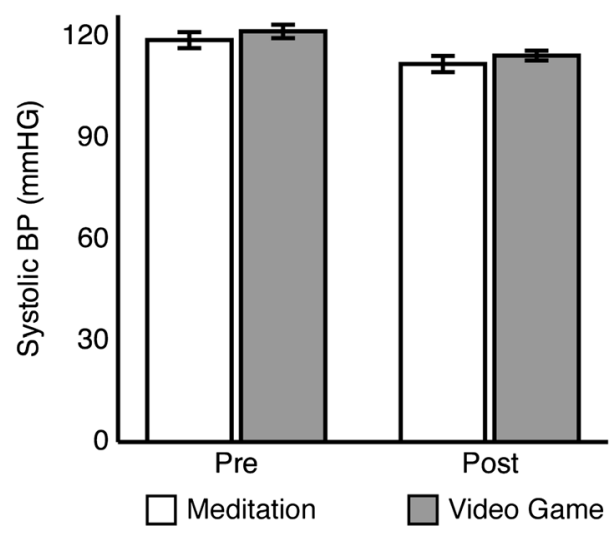

Fig. 3 Pre- and post-systolic blood pressure scores of participants in the mindfulness-meditation (white bars) and video game (grey bars) groups. There was a statistically significant reduction in systolic blood pressure in both participant groups after the intervention $(p<.001) . M+/-1 S E$ 


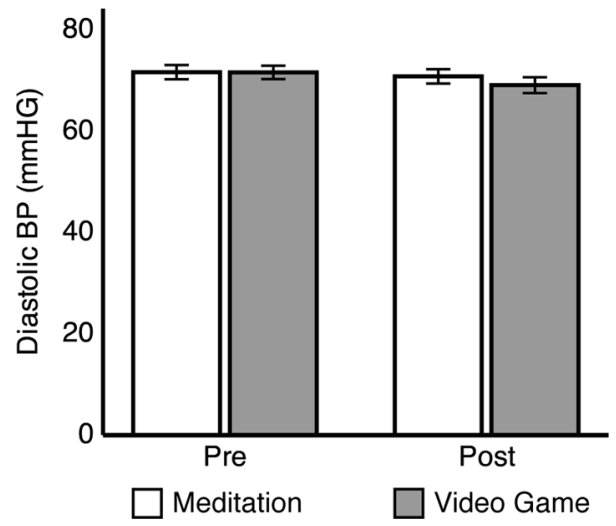

Fig. 4 Pre- and post-diastolic blood pressure scores of participants in the mindfulness-meditation (white bars) and video game (grey bars) groups. There was a statistically significant reduction in diastolic blood pressure in both participant groups after the intervention $(p=.006) . M+/-1 S E$

perceived stress, there was no difference in the degree of reduction across the stress measures between playing a casual video game and participating in a mindfulnessmeditation session. Thus, playing casual video games may be a viable method for stress reduction among undergraduate students.

\section{Casual Video Games and Stress Reduction}

Our study is part of an emerging mosaic of research investigating the effectiveness of casual video games for stress reduction. We found that playing a casual video game, such as Flower, can be an effective medium to lowering psychological and physiological student stress, a finding that is consistent with several studies from the literature (Fish et al. 2014; Pine et al. 2020; Rupp et al. 2017; Russoniello et al. 2009). Among those studies, the most relevant to ours is one by Russoniello et al. (2009), who also explored the connection between casual video games and stress reduction after a 20-min session. In their study, individuals were randomized between a casual video game group and an internet research (control) group. The study observed that those who played a casual video game experienced improved mood and reduced physiological stress compared to baseline, thus supporting our study's observation of casual video games' potential stress-reducing benefit.

To our knowledge, our study is the first to directly compare the effects of playing a casual video game to participating in guided mindfulness-meditation. Although we found that playing a casual video game was just as effective as meditating for physiological stress reduction, we found that participants in the mindfulnessmeditation group enjoyed greater reductions in self-perceived stress. It is possible this finding is due to participant expectation, whereby individuals in our study were more inclined to report greater reductions after meditating than after playing a casual video game because of meditation's widely perceived benefit. Alternatively, it is possible that playing casual video games may be more of a distraction-based strategy, which has been suggested to be less effective than mindfulness-based strategies in reducing stress (Broderick 2005). 


\section{Mindfulness-Meditation and Stress Reduction}

We found that a brief period of body scan meditation reduced blood pressure, heart rate, and self-perceived stress among our participants, findings that are in general agreement with the meditation literature (Barnes et al. 1999; Ditto et al. 2006; Grégoire and Lachance 2015; Hoge et al. 2018; Oman et al. 2008; Park and Han 2017; Pramanik et al. 2010; Rush and Sharma 2017).

Of notable interest is a study by Ditto et al. (2006), who also administered a 20-min body scan and subsequently observed a reduction in the heart rate of their participants. However, unlike our study which found global reductions in blood pressure, Ditto et al. had mixed results. In one experiment, the authors reported no reduction in blood pressure after their participants underwent a body scan session, but in a follow-up experiment, there was evidence for systolic blood pressure to decrease. Although our blood pressure results appear statistically at odds with Ditto et al., they are descriptively quite similar. That is, we observed a much greater decrease of systolic, than diastolic, blood pressure (over four folds greater) among our participants who underwent a body scan and only a marginal decrease in diastolic blood pressure. This finding is also strikingly similar to the MBSR literature, which also reported greater decreases in systolic than diastolic blood pressure following MBSR (Hughes et al. 2013; Momeni et al. 2016; Parswani et al. 2013). A possible explanation for the differences in reduction between systolic and diastolic blood pressures is that, physiologically, systolic blood pressure varies to a greater degree than diastolic blood pressure (Musini and Wright 2009).

Intriguingly, Ditto et al. (2006) observed no difference in the extent to which heart rate and blood pressure decreased between their three intervention groups: body scan, muscle relaxation, and sitting quietly. Our results are generally consistent with this finding, as we also observed no differences in the extent to which heart rate and blood pressure decreased between our two intervention groups: mindfulness-meditation and video game. This lack of difference between undergoing a body scan and other relaxation activities (e.g., playing a casual video game) may suggest, as recently reported in a systematic review, that mindfulness-meditation in general is no better at reducing stress than other relaxation activities (Goyal et al. 2014). That said, it is interesting to note that Ditto et al. (2006) found that a body scan resulted in greater increases in heart rate variability, indicative of reduced stress/anxiety, among their participants than all their other interventions; and we found that self-perceived stress also reduced to a greater extent among the mindfulness-meditation than the video game group. Regardless, our results nevertheless suggest playing a casual video game may offer a viable alternative for stress reduction to mindfulness-meditation, which is especially important given casual video games' accessible nature, ease of use, and popularity among students.

\section{Physiological Effects of Stress-Reducing Activities}

Mindfulness-meditation focuses on increasing self-awareness towards one's situational emotional responses, in the present moment and non-judgmentally (Hölzel et al. 2011; Kabat-Zinn 1994; Tang et al. 2015). Over time, this may lead to decreases in an individual's reactivity towards a negative emotional stimulus. These changes are 
thought to be mediated by brain areas including the ventromedial prefrontal cortex (vmPFC), which may mediate amygdala activity; patients practicing mindfulnessmeditation show increased activity in the vmPFC and reduced activity in the amygdala (Chau et al. 2018; Hölzel et al. 2011; Kral et al. 2018; Zeidan et al. 2014). These neural changes have been associated with increased parasympathetic tone and reduced cortisol levels, presumably reducing physiological and psychological responses to stress (Hölzel et al. 2011). Patients playing non-violent video games have also demonstrated increased vmPFC activity during emotional stimulation (Palaus et al. 2017; Wang et al. 2009). Taken together, these studies suggest the stress-reducing capabilities of mindfulness-meditation and casual video games, such as Flower, may be mediated by upregulation of vmPFC activity.

\section{Limitations and Future Directions}

There is a small possibility that our measurements were influenced by white coat hypertension, a phenomenon where blood pressure is elevated (beyond baseline levels) from fear of visiting a clinician (Myers et al. 2010). Thus, it is possible our participants' initial blood pressure and heart rate were artificially elevated from fear of visiting a research study. If this is the case, the reductions in blood pressure and heart rate we observed might simply reflect a decrease of white coat hypertension (rather than the interventions themselves) as the participants became accustomed to the research environment. Although we acknowledge this possibility, we believe this effect is unlikely in our study. White coat hypertension has previously been shown to be drastically reduced if the blood pressure is taken by a technician rather than a physician (Myers et al. 2010). With this in mind, participants in our study were greeted by an undergraduate student, dressed in their typical attire, and participant blood pressure (and heart rate) subsequently measured by an automated electronic blood pressure cuff. Furthermore, white coat hypertension has been suggested to overestimate blood pressure by $\sim 5 \mathrm{mmHg}$ (Myers 2014), while we observed a reduction greater than $5 \mathrm{mmHg}$ in systolic blood pressure $(7.14 \mathrm{mmHg})$. However, there was only a small decrease in diastolic blood pressure $(1.70 \mathrm{mmHg})$ that is not beyond the average reported white coat hypertension effect. Lastly, our study was not a medical study nor was it conducted in a clinical setting. Nevertheless, future studies of this nature could further decrease the possibility of the white coat hypertension by allowing the experimenter to momentarily leave the room while blood pressure is measured electronically (Myers et al. 2010).

Although the psychological stress measurement used in our study was based on a previously validated survey, PSM-9 (Lemyre and Tessier 2003), we recognize that with any changes, the validity of the original survey may be altered. While we did not test the validity of our modified PSM-9, the changes we made were very minor (see Table 3 in the Appendix) and the calculated Cronbach's alpha suggests both the pre- and postsurveys have good reliability. Nevertheless, it would be important to further assess the psychometric properties of our modified survey instrument in future studies.

Elevated secretion of cortisol is the typical endocrine response to stress. Although heart rate and blood pressure are proxies of stress (Gasperin et al. 2009), cortisol may provide a more accurate measurement. Thus, future studies should investigate how 
cortisol and other primary markers of stress are impacted by interventions such as playing casual video games relative to participating in mindfulness-meditation sessions.

We recognize the elements found within Flower may not be consistent across this entertainment medium. Flower does not share the same gameplay mechanisms as other commercial video games such as Call of Duty or Mario Kart. As highlighted in Mondéjar et al. (2016), video games can contain different components that may elicit different reactions and emotions in their users. For example, it is possible the effectiveness of our video game is due, in part, to the serene environment and music of the game. Flower is based entirely in a simulated outdoor environment, encompassing elements such as meadows, mountains, and trees. Studies have shown, for example, that watching a nature video or listening to calming music can have stress-reducing effects (Chafin et al. 2004; Hansen et al. 2017; Jiang et al. 2016; Parsons et al. 1998). Similarly, we used only one form of meditation in our study. Thus, it is possible that other forms of meditation (e.g., transcendental) may have differential effects on stress. In fact, Sauer-Zavala et al. (2013) reported that a body scan was less effective in improving psychological well-being (e.g., depression/anxiety, emotion regulation) than both sitting meditation and mindful yoga. Thus, future research should explore how different genres of video games and different forms of meditation affect the psychological and physiological levels of stress of their users.

Lastly, one interesting aspect of video game play is its proposed ability to induce a state of flow, which may elicit positive emotions (Michailidis et al. 2018). Although it is unclear if participants in our study achieved a flow state, we think this is unlikely given the game mechanics of Flower. For example, a flow state is thought to be achieved through tasks that are both challenging and have a clear goal (Klasen et al. 2012). Flower, however, is not a particularly challenging game nor does it present the player with clear, explicit goals. Nevertheless, because we did not test for this directly, it would be interesting to investigate in future studies whether a simple, casual video game like Flower is capable of inducing a flow state in participants.

\section{Conclusion}

Overall, we found that playing a casual video game, such as Flower, is an effective strategy to reduce stress. Although mindfulness-meditation was found to have a slight advantage, casual video games may benefit more students, as they are more accessible, easier to use, and more popular among this population. We hope these results could inform initiatives by colleges and universities to better support students, especially during peak stressful times. Additionally, in light of the current COVID-19 pandemic, undergraduate students are facing higher levels of stress and anxiety due to concerns such as fear of infection, finance, and uncertainty about the future (Martinez and Nguyen 2020). Post-secondary institutions could, for example, set up video game stations in student spaces or encourage the use of this medium online, especially during the current COVID-19 pandemic. It would also be important to further investigate the extent to which playing casual video games is beneficial in the long term and whether those benefits are specific to particular game mechanics. 


\section{Appendix}

Table 3 Modified nine-item Psychological Stress Measure (PSM-9)

\begin{tabular}{|c|c|c|c|c|c|c|c|c|}
\hline \begin{tabular}{|l} 
Description of \\
Mood
\end{tabular} & NOT AT ALL & NOT REALLY & VERY LITTLE & A BIT & SOMEWHAT & QUITEA BIT & VERY MUCH & EXTREMELY \\
\hline & 1 & 2 & 3 & 4 & 5 & 6 & 7 & 8 \\
\hline I feel calm. & & & & & & & & \\
\hline $\begin{array}{l}\text { I feel rushed; I d d vet } \\
\text { not seem to have } \\
\text { enough time. }\end{array}$ & & & & & & & & \\
\hline \begin{tabular}{|l} 
I have physical \\
aches and pains \\
sore back, \\
headache, stiff \\
neck, stomach \\
ache. \\
\end{tabular} & & & & & & & & \\
\hline $\begin{array}{l}\text { I feel } \\
\text { preoccupied, } \\
\text { tormented, or } \\
\text { worried. }\end{array}$ & & & & & & & & \\
\hline \begin{tabular}{|l|} 
Iorreed. \\
my thonfused; \\
muddledhts are lack \\
concentration; I \\
cannot focus.
\end{tabular} & & & & & & & & \\
\hline $\begin{array}{l}\text { I feel full of } \\
\text { energy and keen }\end{array}$ & & & & & & & & \\
\hline $\begin{array}{l}\text { If feel a great } \\
\text { weight on my } \\
\text { shoulders. }\end{array}$ & & & & & & & & \\
\hline \begin{tabular}{|l|} 
I have difficulty \\
controlling my \\
reactions, \\
emotions, \\
moods, or \\
gestures. \\
\end{tabular} & & & & & & & & \\
\hline I feel stressed. & & & & & & & & \\
\hline
\end{tabular}

Acknowledgements We would like to thank Dr. Parmjit Singh for graciously offering an abbreviated form of his 20-min body scan for this experiment. We would also like to extend our gratitude to Dr. Douglas E. Colman and Dr. Jason Sumontha for their many helpful comments and discussions.

\section{Declarations}

Ethics Approval This study was approved by the local ethics review board at the University of WisconsinLa Crosse.

Consent to Participate All participants signed an informed consent form prior to participation in the study.

Conflict of Interest The authors declare no competing interests.

\section{References}

Abouserie, R. (1994). Sources and levels of stress in relation to locus of control and self esteem in university students. Educational Psychology, 14(3), 323-330. https://doi.org/10.1080/0144341940140306.

American College Health Association. (2019). American College Health Association-national college health assessment II: reference group executive summary spring 2019. https:/www.acha.org/documents/ncha/ NCHA-II_SPRING_2019_US_REFERENCE_GROUP_EXECUTIVE_SUMMARY.pdf 
Bamber, M. D., \& Schneider, J. K. (2016). Mindfulness-based meditation to decrease stress and anxiety in college students: a narrative synthesis of the research. Educational Research Review, 18, 1-32. https://doi. org/10.1016/j.edurev.2015.12.004.

Barker, S. B., Knisely, J. S., McCain, N. L., Schubert, C. M., \& Pandurangi, A. K. (2010). Exploratory study of stress-buffering response patterns from interaction with a therapy dog. Anthrozoös, 23(1), 79-91. https://oi.org/10.2752/175303710X12627079939341.

Barnes, V. A., Treiber, F. A., \& Davis, H. (2001). Impact of Transcendental Meditation® on cardiovascular function at rest and during acute stress in adolescents with high normal blood pressure. Journal of Psychosomatic Research, 51(4), 597-605. https://doi.org/10.1016/S0022-3999(01)00261-6.

Barnes, V. A., Treiber, F. A., Turner, J. R., Davis, H., \& Strong, W. B. (1999). Acute effects of transcendental meditation on hemodynamic functioning in middle-aged adults. Psychosomatic Medicine, 61(4), 525531. https://doi.org/10.1097/00006842-199907000-00017.

Bledsoe, S., Baskin, J. J., \& Berry, F. (2018). Fear not! How students cope with the fears and anxieties of college life. College Teaching, 66(3), 158-165. https://doi.org/10.1080/87567555.2018.1472064.

Broderick, P. C. (2005). Mindfulness and coping with dysphoric mood: contrasts with rumination and distraction. Cognitive Therapy and Research, 29, 501-510. https://doi.org/10.1007/s10608-005-3888-0.

Burton, A., Burgess, C., Dean, S., Koutsopoulou, G. Z., \& Hugh-Jones, S. (2017). How effective are mindfulness-based interventions for reducing stress among healthcare professionals? A systematic review and meta-analysis. Stress and Health, 33(1), 3-13. https://doi.org/10.1002/smi.2673.

Campbell, R. L., Svenson, L. W., \& Jarvis, G. K. (1992). Perceived level of stress among university undergraduate students in Edmonton, Canada. Perceptual and Motor Skills, 75, 552-554. https://doi. org/10.2466/pms.1992.75.2.552.

Chafin, S., Roy, M., Gerin, W., \& Christenfeld, N. (2004). Music can facilitate blood pressure recovery from stress. British Journal of Health Psychology, 9(3), 393-403. https://doi.org/10.1348/1359107041557020.

Chau, B. K. H., Keuper, K., Lo, M., So, K.-F., Chan, C. C. H., \& Lee, T. M. C. (2018). Meditation-induced neuroplastic changes of the prefrontal network are associated with reduced valence perception in older people. Brain and Neuroscience Advances, 2, 1-12. https://doi.org/10.1177/2398212818771822.

Corbett, C., Egan, J., \& Pilch, M. (2019). A randomised comparison of two 'stress control' programmes: progressive muscle relaxation versus mindfulness body scan. Mental Health \& Prevention, 15, 200163. https://doi.org/10.1016/j.mph.2019.200163.

Ditto, B., Eclache, M., \& Goldman, N. (2006). Short-term autonomic and cardiovascular effects of mindfulness body scan meditation. Annals of Behavioral Medicine, 32(3), 227-234. https://doi.org/10.1207/ s15324796abm3203 9.

Ferguson, C. J., \& Olson, C. K. (2013). Friends, fun, frustration and fantasy: child motivations for video game play. Motivation and Emotion, 37(1), 154-164. https://doi.org/10.1007/s11031-012-9284-7.

Fish, M. T., Russoniello, C. V., \& O'Brien, K. (2014). The efficacy of prescribed casual videogame play in reducing symptoms of anxiety: a randomized controlled study. Games for Health Journal, 3(5), 291-295. https://doi.org/10.1089/g4h.2013.0092.

Gasperin, D., Netuveli, G., Dias-da-Costa, J. S., \& Pattussi, M. P. (2009). Effect of psychological stress on blood pressure increase: a meta-analysis of cohort studies. Cadernos De Saude Publica, 25(4), 715-726.

Gerra, G., Zaimovic, A., Mascetti, G. G., Gardini, S., Zambelli, U., Timpano, M., Raggi, M. A., \& Brambilla, F. (2001). Neuroendocrine responses to experimentally-induced psychological stress in healthy humans. Psychoneuroendocrinology, 26(1), 91-107. https://doi.org/10.1016/S0306-4530(00)00046-9.

Goyal, M., Singh, S., Sibinga, E. M. S., Gould, N. F., Rowland-Seymour, A., Sharma, R., Berger, Z., Sleicher, D., Maron, D. D., Shihab, H. M., Ranasinghe, P. D., Linn, S., Saha, S., Bass, E. B., \& Haythornthwaite, J. A. (2014). Meditation programs for psychological stress and well-being. JAMA Internal Medicine, 174(3), 357-368. https://doi.org/10.1001/jamainternmed.2013.13018.

Grégoire, S., \& Lachance, L. (2015). Evaluation of a brief mindfulness-based intervention to reduce psychological distress in the workplace. Mindfulness, 6, 836-847. https://doi.org/10.1007/s12671-0140328-9.

Grossman, P., Niemann, L., Schmidt, S., \& Walach, H. (2004). Mindfulness-based stress reduction and health benefits: a meta-analysis. Journal of Psychosomatic Research, 57(1), 35-43. https://doi.org/10.1016/ S0022-3999(03)00573-7.

Hansen, M. M., Jones, R., \& Tocchini, K. (2017). Shinrin-yoku (forest bathing) and nature therapy: a state-ofthe-art review. International Journal of Environmental Research and Public Health, 14(8), 851. https:// doi.org/10.3390/ijerph14080851.

Hoge, E. A., Bui, E., Palitz, S. A., Schwarz, N. R., Owens, M. E., Johnston, J. M., Pollack, M. H., \& Simon, N. M. (2018). The effect of mindfulness meditation training on biological acute stress responses in 
generalized anxiety disorder. Psychiatry Research, 262, 328-332. https://doi.org/10.1016/j.psychres. 2017.01.006.

Hölzel, B. K., Lazar, S. W., Gard, T., Schuman-Olivier, Z., Vago, D. R., \& Ott, U. (2011). How does mindfulness meditation work? Proposing mechanisms of action from a conceptual and neural perspective. Perspectives on Psychological Science, 6(6), 537-559. https://doi.org/10.1177/1745691611419671.

Huberty, J., Green, J., Glissmann, C., Larkey, L., Puzia, M., \& Lee, C. (2019). Efficacy of the mindfulness meditation mobile app "Calm" to reduce stress among college students: randomized controlled trial. JMIR mHealth and uHealth, 7(6), e14273. https://doi.org/10.2196/14273.

Hughes, J. W., Fresco, D. M., Myerscough, R., van Dulmen, M., Carlson, L. E., \& Josephson, R. (2013). Randomized controlled trial of mindfulness-based stress reduction for prehypertension. Psychosomatic Medicine, 75(8), 721-728. https://doi.org/10.1097/PSY.0b013e3182a3e4e5.

Jiang, J., Rickson, D., \& Jiang, C. (2016). The mechanism of music for reducing psychological stress: music preference as a mediator. The Arts in Psychotherapy, 48, 62-68. https://doi.org/10.1016/j.aip.2016.02. 002.

Jones, C. M., Scholes, L., Johnson, D., Katsikitis, M., \& Carras, M. C. (2014). Gaming well: links between videogames and flourishing mental health. Frontiers in Psychology, 5, 260. https://doi.org/10.3389/fpsyg. 2014.00260.

Kabat-Zinn, J. (1994). Wherever you go, there you are: mindfulness meditation in everyday life. Hyperion.

Kang, Y. S., Choi, S. Y., \& Ryu, E. (2009). The effectiveness of a stress coping program based on mindfulness meditation on the stress, anxiety, and depression experienced by nursing students in Korea. Nurse Education Today, 29(5), 538-543. https://doi.org/10.1016/j.nedt.2008.12.003.

Kelly, J. J., Mangos, G., Williamson, P. M., \& Whitworth, J. A. (1998). Cortisol and hypertension. Clinical and Experimental Pharmacology and Physiology, 25(S1), S51-S56. https://doi.org/10.1111/j.1440-1681. 1998.tb02301.x.

Khoury, B., Sharma, M., Rush, S. E., \& Fournier, C. (2015). Mindfulness-based stress reduction for healthy individuals: a meta-analysis. Journal of Psychosomatic Research, 78(6), 519-528. https://doi.org/10. 1016/j.jpsychores.2015.03.009.

Klasen, M., Weber, R., Kircher, T. T. J., Mathiak, K. A., \& Mathiak, K. (2012). Neural contributions to flow experience during video game playing. Social Cognitive and Affective Neuroscience, 7(4), 485-495. https://doi.org/10.1093/scan/nsr021.

Kral, T. R. A., Schuyler, B. S., Mumford, J. A., Rosenkranz, M. A., Lutz, A., \& Davidson, R. J. (2018). Impact of short- and long-term mindfulness meditation training on amygdala reactivity to emotional stimuli. NeuroImage, 181, 301-313. https://doi.org/10.1016/j.neuroimage.2018.07.013.

Lemay, V., Hoolahan, J., \& Buchanan, A. (2019). Impact of a yoga and meditation intervention on students' stress and anxiety levels. American Journal of Pharmaceutical Education, 83(5), 747-752. https:/doi. org/10.5688/ajpe7001.

Lemyre, L., \& Lalande-Markon, M.-P. (2009). Psychological stress measure (PSM-9): integration of an evidence-based approach to assessment, monitoring, and evaluation of stress in physical therapy practice. Physiotherapy Theory and Practice, 25(5-6), 453-462. https://doi.org/10.1080/09593980902886321.

Lemyre, L., \& Tessier, R. (2003). Measuring psychological stress: concept, model, and measurement instrument in primary care research. Canadian Family Physician, 49, 1159-1160.

Lenhart, A., Jones, S., \& MacGill, A. (2008). Adults and video games. https://www.pewresearch.org/internet/ 2008/12/07/adults-and-video-games/

Levoy, E., Lazaridou, A., Brewer, J., \& Fulwiler, C. (2017). An exploratory study of mindfulness based stress reduction for emotional eating. Appetite, 109, 124-130. https://doi.org/10.1016/j.appet.2016.11.029.

Manikandan, S. (2010). Data transformation. Journal of Pharmacology and Pharmacotherapeutics, 1(2), 126-127. https://doi.org/10.4103/0976-500X.72373.

Mantzios, M., \& Giannou, K. (2018). When did coloring books become mindful? Exploring the effectiveness of a novel method of mindfulness-guided instructions for coloring books to increase mindfulness and decrease anxiety. Frontiers in Psychology, 9, 56. https://doi.org/10.3389/fpsyg.2018.00056.

Mantzios, M., Hussain, H., Hussain, A., Egan, H., \& Scanlon, P. (2019). Adult colouring: the effect of appbased vs. pen-and-paper colouring on mindfulness and anxiety. Health Psychology Report, 7(4), 286295. https://doi.org/10.5114/hpr.2019.87312.

Martinez, A., \& Nguyen, S. (2020). The impact of COVID-19 on college student well-being. https:// vtechworks.lib.vt.edu/bitstream/handle/10919/99741/2020ImpactCOVID19CollegeStudent.pdf? sequence $=1$

McFadden, K. L., Healy, K. M., Hoversten, K. P., Ito, T. A., \& Hernández, T. D. (2012). Efficacy of acupressure for non-pharmacological stress reduction in college students. Complementary Therapies in Medicine, 20(4), 175-182. https://doi.org/10.1016/j.ctim.2011.12.003. 
Michailidis, L., Balaguer-Ballester, E., \& He, X. (2018). Flow and immersion in video games: the aftermath of a conceptual challenge. Frontiers in Psychology, 9, 1682. https://doi.org/10.3389/fpsyg.2018.01682.

Momeni, J., Omidi, A., Raygan, F., \& Akbari, H. (2016). The effects of mindfulness-based stress reduction on cardiac patients' blood pressure, perceived stress, and anger: a single-blind randomized controlled trial. Journal of the American Society of Hypertension, 10(10), 763-771. https://doi.org/10.1016/j.jash.2016. 07.007.

Mondéjar, T., Hervás, R., Johnson, E., Gutierrez, C., \& Latorre, J. M. (2016). Correlation between videogame mechanics and executive functions through EEG analysis. Journal of Biomedical Informatics, 63, 131140. https://doi.org/10.1016/j.jbi.2016.08.006.

Musini, V. M., \& Wright, J. M. (2009). Factors affecting blood pressure variability: lessons learned from two systematic reviews of randomized controlled trials. PLOS ONE, 4(5), e5673. https://doi.org/10.1371/ journal.pone.0005673.

Myers, M. G. (2014). Eliminating the human factor in office blood pressure measurement. The Journal of Clinical Hypertension, 16(2), 83-86. https://doi.org/10.1111/jch.12252.

Myers, M. G., Godwin, M., Dawes, M., Kiss, A., Tobe, S. W., \& Kaczorowski, J. (2010). Measurement of blood pressure in the office: recognizing the problem and proposing the solution. Hypertension, 55(2), 195-200. https://doi.org/10.1161/HYPERTENSIONAHA.109.141879.

Nyklíček, I., Mommersteeg, P. M. C., van Beugen, S., Ramakers, C., \& van Boxtel, G. J. (2013). Mindfulness-based stress reduction and physiological activity during acute stress: a randomized controlled trial. Health Psychology, 32(10), 1110-1113. https://doi.org/10.1037/a0032200

Oman, D., Shapiro, S. L., Thoresen, C. E., Plante, T. G., \& Flinders, T. (2008). Meditation lowers stress and supports forgiveness among college students: a randomized controlled trial. Journal of American College Health, 56(5), 569-578. https://doi.org/10.3200/JACH.56.5.569-578.

Palaus, M., Marron, E. M., Viejo-Sobera, R., \& Redolar-Ripoll, D. (2017). Neural basis of video gaming: a systematic review. Frontiers in Human Neuroscience, 11, 248. https://doi.org/10.3389/fnhum.2017. 00248.

Palmer, A., \& Rodger, S. (2009). Mindfulness, stress, and coping among university students. Canadian Journal of Counselling and Psychotherapy, 43(3), 198-212 https://journalhosting.ucalgary.ca/index.php/ rcc/article/view/61055.

Park, S.-H., \& Han, K. S. (2017). Blood pressure response to meditation and yoga: a systematic review and meta-analysis. The Journal of Alternative and Complementary Medicine, 23(9), 685-695. https://doi.org/ 10.1089/acm.2016.0234.

Parsons, R., Tassinary, L. G., Ulrich, R. S., Hebl, M. R., \& Grossman-Alexander, M. (1998). The view from the road: implications for stress recovery and immunization. Journal of Environmental Psychology, 18(2), 113-140. https://doi.org/10.1006/jevp.1998.0086.

Parswani, M. J., Sharma, M. P., \& Iyengar, S. (2013). Mindfulness-based stress reduction program in coronary heart disease: a randomized control trial. International Journal of Yoga, 6(2), 111-117. https://doi.org/10. 4103/0973-6131.113405.

Pine, R., Fleming, T., McCallum, S., \& Sutcliffe, K. (2020). The effects of casual videogames on anxiety, depression, stress, and low mood: a systematic review. Games for Health Journal, 9(4), 255-264. https:// doi.org/10.1089/g4h.2019.0132.

Pramanik, T., Pudasaini, B., \& Prajapati, R. (2010). Immediate effect of a slow pace breathing exercise Bhramari pranayama on blood pressure and heart rate. Nepal Medical College Journal, 12(3), 154-157.

Ratanasiripong, P., Park, J. F., Ratanasiripong, N., \& Kathalae, D. (2015). Stress and anxiety management in nursing students: biofeedback and mindfulness meditation. Journal of Nursing Education, 54(9), 520524. https://doi.org/10.3928/01484834-20150814-07.

Regehr, C., Glancy, D., \& Pitts, A. (2013). Interventions to reduce stress in university students: a review and meta-analysis. Journal of Affective Disorders, 148(1), 1-11. https://doi.org/10.1016/j.jad.2012.11.026.

Reinecke, L. (2009). Games and recovery: the use of video and computer games to recuperate from stress and strain. Journal of Media Psychology, 21(3), 126-142. https://doi.org/10.1027/1864-1105.21.3.126.

Rieger, D., Frischlich, L., Wulf, T., Bente, G., \& Kneer, J. (2015). Eating ghosts: the underlying mechanisms of mood repair via interactive and noninteractive media. Psychology of Popular Media Culture, 4(2), 138-154 https://doi.org/10.1037/ppm0000018.

Rosenzweig, S., Reibel, D. K., Greeson, J. M., Brainard, G. C., \& Hojat, M. (2003). Mindfulness-based stress reduction lowers psychological distress in medical students. Teaching and Learning in Medicine, 15(2), 88-92. https://doi.org/10.1207/S15328015TLM1502_03.

Roy, A., \& Ferguson, C. J. (2016). Competitively versus cooperatively? An analysis of the effect of game play on levels of stress. Computers in Human Behavior, 56, 14-20. https://doi.org/10.1016/j.chb.2015.11.020. 
Rupp, M. A., Sweetman, R., Sosa, A. E., Smither, J. A., \& McConnell, D. S. (2017). Searching for affective and cognitive restoration: examining the restorative effects of casual video game play. Human Factors: The Journal of the Human Factors and Ergonomics Society, 59(7), 1096-1107. https://doi.org/10.1177/ 0018720817715360.

Rush, S. E., \& Sharma, M. (2017). Mindfulness-based stress reduction as a stress management intervention for cancer care: a systematic review. Journal of Evidence-Based Complementary \& Alternative Medicine, 22(2), 348-360. https://doi.org/10.1177/2156587216661467.

Russoniello, C. v., O’Brien, K., \& Parks, J. M. (2009). The effectiveness of casual video games in improving mood and decreasing stress. Journal of Cybertherapy and Rehabilitation, 2(1), 53-66.

Saleh, D., Camart, N., \& Romo, L. (2017). Predictors of stress in college students. Frontiers in Psychology, 8, 19. https://doi.org/10.3389/fpsyg.2017.00019.

Saraswati, S. (2009). Yoga Nidra. Yoga Publications Trust.

Sauer-Zavala, S. E., Walsh, E. C., Eisenlohr-Moul, T. A., \& Lykins, E. L. B. (2013). Comparing mindfulnessbased intervention strategies: differential effects of sitting meditation, body scan, and mindful yoga. Mindfulness, 4, 383-388. https://doi.org/10.1007/s12671-012-0139-9.

Schultchen, D., Messner, M., Karabatsiakis, A., Schillings, C., \& Pollatos, O. (2019). Effects of an 8-week body scan intervention on individually perceived psychological stress and related steroid hormones in hair. Mindfulness, 10, 2532-2543. https://doi.org/10.1007/s12671-019-01222-7.

Shapiro, S. L., Schwartz, G. E., \& Bonner, G. (1998). Effects of mindfulness-based stress reduction on medical and premedical students. Journal of Behavioral Medicine, 21, 581-599. https://doi.org/10.1023/ A:1018700829825.

Shearer, A., Hunt, M., Chowdhury, M., \& Nicol, L. (2016). Effects of a brief mindfulness meditation intervention on student stress and heart rate variability. International Journal of Stress Management, 23(2), 232-254. https://doi.org/10.1037/a0039814.

Soyoof, A., \& McLay, K. F. (2019). The impact of video game intervention on reducing stress and enhancing language achievement and communication skills. International Journal of Pedagogies and Learning, 14(1), 45-58.

Stanley, S., \& Bhuvaneswari, G. M. (2016). Stress, anxiety, resilience and coping in social work students (a study from India). Social Work Education, 35(1), 78-88. https://doi.org/10.1080/02615479.2015. 1118451.

Tang, Y.-Y., Hölzel, B. K., \& Posner, M. I. (2015). The neuroscience of mindfulness meditation. Nature Reviews Neuroscience, 16, 213-225. https://doi.org/10.1038/nrn3916.

Thomas, N. J., \& Martin, F. H. (2010). Video-arcade game, computer game and Internet activities of Australian students: participation habits and prevalence of addiction. Australian Journal of Psychology, 62(2), 59-66. https://doi.org/10.1080/00049530902748283.

Ussher, M., Spatz, A., Copland, C., Nicolaou, A., Cargill, A., Amini-Tabrizi, N., \& McCracken, L. M. (2014). Immediate effects of a brief mindfulness-based body scan on patients with chronic pain. Journal of Behavioral Medicine, 37, 127-134. https://doi.org/10.1007/s10865-012-9466-5.

Vogel, S., \& Schwabe, L. (2016). Learning and memory under stress: implications for the classroom. $N p j$ Science of Learning, 1(1), 16011. https://doi.org/10.1038/npjscilearn.2016.11.

Wack, E., \& Tantleff-Dunn, S. (2009). Relationships between electronic game play, obesity, and psychosocial functioning in young men. Cyberpsychology \& Behavior, 12(2), 241-244. https://doi.org/10.1089/cpb. 2008.0151.

Wang, Y., Mathews, V. P., Kalnin, A. J., Mosier, K. M., Dunn, D. W., Saykin, A. J., \& Kronenberger, W. G. (2009). Short term exposure to a violent video game induces changes in frontolimbic circuitry in adolescents. Brain Imaging and Behavior, 3, 38-50. https://doi.org/10.1007/s11682-008-9058-8.

Warnecke, E., Quinn, S., Ogden, K., Towle, N., \& Nelson, M. R. (2011). A randomised controlled trial of the effects of mindfulness practice on medical student stress levels. Medical Education, 45(4), 381-388. https://doi.org/10.1111/j.1365-2923.2010.03877.x.

Whitbourne, S. K., Ellenberg, S., \& Akimoto, K. (2013). Reasons for playing casual video games and perceived benefits among adults 18 to 80 years old. Cyberpsychology, Behavior and Social Networking, 16(12), 892-897. https://doi.org/10.1089/cyber.2012.0705.

Zeidan, F., Martucci, K. T., Kraft, R. A., McHaffie, J. G., \& Coghill, R. C. (2014). Neural correlates of mindfulness meditation-related anxiety relief. Social Cognitive and Affective Neuroscience, 9(6), 751759. https://doi.org/10.1093/scan/nst041.

Zhang, X., Wang, H., Xia, Y., Liu, X., \& Jung, E. (2012). Stress, coping, and suicide ideation in Chinese college students. Journal of Adolescence, 35(3), 683-690. https://doi.org/10.1016/j.adolescence.2011.10. 003 . 


\section{Affiliations}

\section{Veeral Desai ${ }^{1,2} \cdot$ Arnav Gupta $^{3}$ - Lucas Andersen ${ }^{4}$ - Bailey Ronnestrand ${ }^{4}$. Michael Wong ${ }^{1,4,5}$}

1 Bachelor of Health Sciences Program, McMaster University, Hamilton, Canada

2 Faculty of Medicine, Queen's University, Kingston, Canada

3 Faculty of Medicine, University of Ottawa, Ottawa, Canada

4 Psychology Department, University of Wisconsin-La Crosse, La Crosse, USA

5 Department of Psychiatry and Behavioural Neurosciences, McMaster University, Hamilton, Canada 